\title{
Anterior cervical discectomy with fusion in patients with cervical disc degeneration: a prospective outcome study of 258 patients (181 fused with autologous bone graft and 77 fused with a PEEK cage)
}

\author{
Bjarne Lied ${ }^{1,2,3^{*}}$, Paal Andre Roenning ${ }^{2}$, Jarle Sundseth' ${ }^{1}$ Eirik Helseth ${ }^{1,2,3}$
}

\begin{abstract}
Background: Anterior cervical discectomy with fusion (ACDF) is challenging with respect to both patient selection and choice of surgical procedure. The aim of this study was to evaluate the clinical outcome of ACDF, with respect to both patient selection and choice of surgical procedure: fusion with an autologous iliac crest graft (AICG) versus fusion with an artificial cage made of polyetheretherketone (PEEK).

Methods: This was a non-randomized prospective single-center outcome study of 258 patients who underwent ACDF for cervical disc degeneration (CDD). Fusion was attained with either tricortical AICG or PEEK cages without additional anterior plating, with treatment selected at surgeon's discretion. Radicular pain, neck-pain, headache and patient satisfaction with the treatment were scored using the visual analogue scale (VAS).

Results: The median age was 47.5 (28.3-82.8) years, and $44 \%$ of patients were female. 59\% had single-level ACDF, $40 \%$ had two level ACDF and 1\% had three-level ACDF. Of the patients, 181 were fused with AICG and 77 with a PEEK-cage. After surgery, the patients showed a significant reduction in radicular pain $(\triangle V A S=3.05$ ), neck pain $(\triangle V A S=2.30)$ and headache $(\triangle V A S=0.55)$. Six months after surgery, $48 \%$ of patients had returned to work: however $24 \%$ were still receiving workers' compensation.

Using univariate and multivariate analyses we found that high preoperative pain intensity was significantly associated with a decrease in pain intensity after surgery, for all three pain categories. There were no significant correlations between pain relief and the following patient characteristics: fusion method (AICG or PEEK-cage), sex, age, number of levels fused, disc level fused, previous neck surgery (except for neck pain), previous neck trauma, or preoperative symptom duration. Two hundred out of the 256 (78\%) patients evaluated the surgical result as successful. Only 27/256 (11\%) classified the surgical result as a failure. Patient satisfaction was significantly associated with pain relief after surgery.
\end{abstract}

Conclusions: ACDF is an effective treatment for radicular pain in selected patients with CDD after six months follow up.

Because of similar clinical outcomes and lack of donor site morbidity when using PEEK, we now prefer fusion with PEEK cage to AICG.

Lengthy symptom duration was not a negative prognostic marker in our patient population.

The number of patients who returned to work 6 months after surgery was lower than expected.

\footnotetext{
* Correspondence: bjarne.lied@ulleval.no

'Department of Neurosurgery-Rikshospitalet, Oslo University Hospital, N-0027 Oslo, Norway
} 


\section{Background}

The vast majority of patients with symptomatic cervical disc degeneration (CDD) respond well to conservative treatment [1]. For nonresponders, surgical treatment using ACDF is an option for selected patients [2]. In the USA, the annual incidence of surgery for CDD is 50-60 per 100000 inhabitants [3]. Selection of adequate candidates for ACDF surgery is a continuous challenge. According to the literature, the following are potential positive predictive preoperative markers: intense radicular pain, low disability, young age, soft disc disease in one segmental level, male sex, non-smoker status, presence of a correlation between radiological and clinical findings, good hand strength, good active range of motion in the neck, and no spinal litigations [4,5]. In surgery for lumbar disc degeneration, symptom duration $>6$ months is regarded as a negative prognostic factor [6]. This is also reported to be true for ACDF surgery [7]. This is intriguing, as many patients referred to ACDF surgery have symptom duration $>6$ months. Is surgery in these patients worthwhile or futile?

The gold standard for ACDF has been fusion with an AICG [8-10]. This is a relatively safe procedure with few complications [11-13]. However, this surgical procedure has been hampered by iliac crest donor site morbidity. This has led to a growing interest in artificial cages made of various materials, including tantalium blocks, titanium, carbonfiber and polyetheretherketone (PEEK), to replace the AICG [12,14-18]. In our hospital since 2004 we have gradually shifted from AICG to PEEK. We found no increase in complications after shifting to fusion with a PEEK cage [11].

We prospectively registered all ACDF patients followed in our department from 2003-2005 and used this information to address the following questions.

1. What improvement in clinical outcomes can be expected after ACDF for CDD with regard to radicular pain, neck pain, headache, and return to work?

2. Did the gradual shift from fusion with AICG to fusion with PEEK cage, in our department during the study period, influence outcomes?

3. Do symptom duration or other preoperative clinical variables correlate with outcome after ACDF for CDD in our series?

\section{Methods}

This was a prospective single-center study of patients who underwent single-, two-, or three-level ACDF for CDD. The study was performed at the Oslo University Hospital-Rikshospitalet in Oslo from 2003 to 2005. All surgeons were asked to participate in a prospective registration of clinical parameters. During this period, 390 patients (total group) were eligible for inclusion and we obtained complete preoperative and follow-up data for 258 patients (66.1\%) (study group). Only the 258 patients with complete data sets were included in the analysis.

\section{Inclusion criteria $(1+2)$}

The inclusion criteria were

1. One or more of the following symptoms and signs of CDD:
a. Persistent severe radicular pain not responding to conservative management for three months.
b. Cervical radiculopathy with progressive paresis.
c. Selected cases with myelopathy secondary to cer- vical spinal canal stenosis that can be adequately decompressed with ACDF.
d. Selected cases with mainly neck pain and head- ache and less radicular pain.

2. MRI- documented CDD with compression of cervical nerve roots or spinal cord, which most likely explain the clinical symptoms and signs.

\section{Exclusion criteria}

The exclusion criteria were

1. Cervical trauma within the past four weeks.

2. Cervical neoplasia.

3. Ongoing cervical infection.

\section{Diagnostic work-up}

The diagnostic work-up included

1. Clinical and neurological examination.

2. Cervical MRI (cervical CT-myelography was used in one case where MRI was contraindicated due to a permanent pacemaker).

\section{ACDF}

In all patients, we used an anterior approach to the cervical spine with a right-sided skin incision, as originally described by Robinson and Smith [9]. A self-retractor was mounted after verification of the levels of interest using fluoroscopy, (Shadow -line, V. Mueller Neuro/ Spine Product, Cardinal Health, San Carlos, CA).

In most patients, an operating microscope was used and the disc was removed with a high-speed drill (Midas Rex, Medtronic, Memphis, TN). Removal of the posterior longitudinal ligament and the final decompression of the nerve roots were performed using small rongeurs. Bilateral nerve root decompression was always performed, even in patients with unilateral symptoms. After the procedure, distraction was applied using the Shadow-line Distraction System (V. Mueller Neuro/Spine Product, Cardinal Health). Fusion was attained with either tricortical AICG or PEEK cages (Cervios, Stratec Medical, Oberdorf, Switzerland), at the discretion of the surgeon. After 
removal of the Shadow-line distracters, the screw holes were plugged with bone wax (Ethicon, Johnson \& Johnson, Somerville, NJ) to prevent postoperative bleeding. Wound drainage was not routinely used. A single dose of cephalothin $(30 \mathrm{mg} / \mathrm{kg})$, which was used as infection prophylaxis, was administered 15-30 min before the skin incision [19-21].

\section{Iliac crest auto graft}

The tricortical AICG was harvested from the right iliac crest. Care was taken to preserve the anterior $2 \mathrm{~cm}$ of the iliac crest and the lateral cutaneous femoral nerve. The bone grafts were harvested using an oscillating saw and a graft cutter, and the bone bed was waxed with bone wax (Ethicon, Johnson \& Johnson, USA). Wound drainage was not routinely used, and the surrounding soft tissue was infiltrated with $20 \mathrm{ml}$ of bupivacaine after wound closure.

\section{Postoperative care}

The patients were observed in a recovery unit for the first 4-6 h after surgery, and were then transferred to the regular neurosurgical ward. All patients were mobilized with a stiff collar within $24 \mathrm{~h}$ after surgery. Almost all patients were discharged from our hospital to the referring neurological department 48-72 h after surgery. All patients were encouraged repeatedly to participate in normal activities 6-14 weeks after surgery. A final clinical examination was performed 6 months after surgery in our outpatient clinic.

\section{Prospective registration of clinical parameters}

The parameters registered the day before surgery included age, sex, symptom duration before surgery (months), previous surgery for CDD, previous neck trauma, working status, radicular pain, neck pain, headache, myelopathy (yes/no), and paresis (muscular strength graded according to the Royal Medical Research Council of Great Britain, where 5 is normal strength and 0 is total paralysis in the affected muscle group)[22]. Each of the three pain categories was scored using a VAS, where 0 indicated no pain and 10 represented extreme pain[23].

As the clinical impact of changes in VAS scores less than \pm 2 is unclear, we estimated the number of patients that had changes in VAS scores of more than \pm 2 for the three pain categories [24,25]. The parameters registered during surgery included: number of levels fused (single-level, two-level, or three-level fusion), level fused (C3/C4, C4/C5, C5/C6, C6/7 or C7/Th1) and fusion type (AICG or PEEKcage). The following parameters were registered at the 6-month follow-up visit in our outpatient clinic: radicular pain, neck pain, headache, myelopathy (a diagnosis of myelopathy required neurological signs of upper motor neuron affection as Babinsky sign, hyperreflexia or increased muscular tone), paresis, working status and patient satisfaction with the surgical treatment. Patient satisfaction was measured using a VAS scale, where a score of 0 indicated that the patient was not at all satisfied with the result of $A C D F$ and a score of 10 indicated that the patient was very satisfied with the surgical outcomes $[26,27]$. We defined a VAS score $\geq 8$ as a success, while a score $\leq 5$ was regarded as a failure.

\section{Surgery-related complications}

We have previously published our complications in 390 consecutive ACDF operations, which included 278 patients fused with AICG and 112 patients fused with a PEEK graft [11].

\section{Database and statistical analyses}

For linear regression analysis, we first performed a univariate analysis, followed by multivariate modeling introducing all the variables, in an exploratory fashion. The linearity assumption of the linear regression was checked using a plot of the fitted regression line compared with a locally weighted nonparametric scatterplot of the outcome variable against the predictor. Homoscedasticity was checked by graphing residuals versus predicted and observed values. Finally, normality of residuals was checked using boxplots, histograms, and quantile plots of residuals. Ordinal variables were also checked for linearity using a nested likelihood ratio test.

Some of our variables displayed heteroscedasticity, therefore, we repeated the analyses using both the Huber-White sandwich estimator of variance relaxing the homoscedasticity assumption and bootstrapped regressions with 1.000 repetitions. The results of these analyses were in agreement with the findings of our traditional regression results, which allowed us to take a relaxed stance toward the heteroscedastic findings in some of our models. Standard paired t-tests, chisquared, and z-tests for proportions were also used. Significance was set at alpha $<0.05$. The Stata v10.1 (Stata Corp, Austin, TX) software was used in all analyses.

\section{Ethics}

The Data Protection Officials of the Rikshospitalet approved the study. All patients gave signed informed consent for entry of the data into the database and for the subsequent prospective study.

\section{Results}

\section{Baseline clinical characteristics}

Of the 390 patients eligible for inclusion in this study (total group), we obtained complete preoperative- and follow-up data for 258 patients (66.1\%) (study group). 
Table 1 Patient characteristics.

\begin{tabular}{|c|c|c|c|c|c|}
\hline ACDF & $\begin{array}{c}\text { Study group } \\
\mathrm{N}=258\end{array}$ & $\begin{array}{c}\text { Total group } \\
\mathrm{N}=390\end{array}$ & & p-value & \\
\hline Females - no of patients (\%) & $114(44)$ & $178(46)$ & & $0.72^{\text {prop }}$ & \\
\hline Median age (range) - (years) & $47.5(28.3-82.8)$ & $47.7(26.9-82.8)$ & & 0.73 & \\
\hline \multicolumn{6}{|l|}{ Levels per procedure - no of patients (\%) } \\
\hline One level & $152(59)$ & $240(61)$ & 0.50 & & \\
\hline Two levels & $104(40)$ & $148(38)$ & 0.55 & & \\
\hline Three levels & $2(1)$ & $2(1)$ & 0.68 & & $0.75^{\times 2}$ \\
\hline \multicolumn{6}{|l|}{ Level - no of patients (\%) } \\
\hline $\mathrm{C} 3 / \mathrm{C} 4$ & $7(3)$ & $7(2)$ & 0.43 & & \\
\hline $\mathrm{C} 4 / \mathrm{C} 5$ & $38(15)$ & $56(14)$ & 0.90 & & \\
\hline $\mathrm{C} 5 / \mathrm{C} 6$ & $182(71)$ & $266(68)$ & 0.53 & & \\
\hline $\mathrm{C} 6 / \mathrm{C} 7$ & $137(53)$ & $207(53)$ & 0.99 & & \\
\hline $\mathrm{C} 7 / \mathrm{Th} 1$ & $2(1)$ & $6(2)$ & 0.39 & & $0.85^{x^{2}}$ \\
\hline \multicolumn{6}{|l|}{ Method of fusion - no of patients (\%) } \\
\hline Autologous bone graft & $181(70)$ & $278(71)$ & 0.76 & & \\
\hline PEEK* cage & $77(30)$ & $112(29)$ & 0.76 & & $0.76^{x^{2}}$ \\
\hline \multicolumn{6}{|l|}{ Symptoms - no of patients (\%) } \\
\hline Radiculopathy & $206(80)$ & $309(79)$ & & 0.85 & \\
\hline Radiculopathy and myelopathy & $36(14)$ & $50(13)$ & & 0.86 & \\
\hline Myelopathy & $9(3)$ & $18(5)$ & & 0.48 & \\
\hline No radiculopathy or myelopathy & 7 (3) & $13(3)$ & & 0.66 & \\
\hline Previous ACDF - no of patients (\%) & $11(4)$ & $18(5)$ & & 0.83 & \\
\hline Previous neck trauma - no of patients (\%) & $23(9)$ & $26(7)$ & & 0.29 & \\
\hline
\end{tabular}

*Polyetheretherketone

The patient characteristics for both groups are included in Table 1. No significant differences were found between the groups with respect to baseline clinical characteristics. Only the 258 patients with complete data sets were included in the analyses.

\section{Pain relief after surgery}

We found a significant reduction in radicular pain, neck pain, and headache after surgery in the study group (Table 2). The reduction was most pronounced for radicular pain and neck pain. Using univariate and multivariate analyses we found that high preoperative pain intensity was significantly associated with a decrease in pain intensity after surgery, for all three pain categories. There were no significant correlations between pain relief and the following patients characteristics: sex, age, number of levels fused, disc level fused, fusion method (AICG versus PEEK-cage), previous neck surgery (except for neck pain), previous neck trauma, or preoperative symptom duration (Table 3). As the clinical impact of

Table 2 Intensity of pain measured using the VAS scale before surgery (preop) and 6 months after surgery (postop).

\begin{tabular}{|c|c|c|c|c|c|c|}
\hline \multirow[b]{3}{*}{ Paired samples } & \multirow[b]{3}{*}{$\mathbf{N}$} & & \multicolumn{3}{|c|}{ Paired differences } & \multirow[b]{3}{*}{ Sig. (two-tailed) } \\
\hline & & & & $95 \% \mathrm{C}$ & erval & \\
\hline & & Mean & Mean & Lower & Upper & \\
\hline \multirow[t]{2}{*}{ Preop radicular pain } & 258 & 7.47 & & & & \\
\hline & & & 3.05 & 2.65 & 3.45 & 0.000 \\
\hline Postop radicular pain & 258 & 4.42 & & & & \\
\hline \multirow[t]{2}{*}{ Preop neck pain } & 255 & 6.45 & & & & \\
\hline & & & 2.30 & 1.90 & 2.71 & 0.000 \\
\hline Postop neck pain & 255 & 4.15 & & & & \\
\hline \multirow[t]{2}{*}{ Preop headache } & 254 & 3.63 & & & & \\
\hline & & & 0.55 & 0.22 & 0.89 & 0.001 \\
\hline Postop headache & 254 & 3.08 & & & & \\
\hline
\end{tabular}

(Paired sample t-test). 
Table 3 Univariate and multivariate Cox regression model of potential predictors of outcome.

\begin{tabular}{|c|c|c|c|c|c|c|}
\hline & \multicolumn{2}{|c|}{ Delta radicular pain } & \multicolumn{2}{|c|}{ Delta neck pain } & \multicolumn{2}{|c|}{ Delta headache } \\
\hline & Univariate & Multivariate & Univariate & Multivariate & Univariate & Multivariate \\
\hline Sex & $\begin{array}{c}0.25 \\
{[-0.56,1.05]}\end{array}$ & $\begin{array}{c}0.031 \\
{[-0.73,0.79]}\end{array}$ & $\begin{array}{c}0.40 \\
{[-0.41,1.22]}\end{array}$ & $\begin{array}{c}0.18 \\
{[-0.49,0.85]}\end{array}$ & $\begin{array}{c}0.34 \\
{[-0.34,1.01]}\end{array}$ & $\begin{array}{c}0.15 \\
{[-0.45,0.74]}\end{array}$ \\
\hline Age & $\begin{array}{c}-0.035 \\
{[-0.08,0.01]}\end{array}$ & 0 & $\begin{array}{c}0.0095 \\
{[-0.03,0.05]}\end{array}$ & $\begin{array}{l}0 \\
.\end{array}$ & $\begin{array}{c}-0.000059 \\
{[-0.04,0.04]}\end{array}$ & 0 \\
\hline Type of fusion & $\begin{array}{c}0.0077 \\
{[-0.87,0.88]}\end{array}$ & $\begin{array}{c}0.21 \\
{[-0.61,1.04]}\end{array}$ & $\begin{array}{c}0.096 \\
{[-0.78,0.98]}\end{array}$ & $\begin{array}{c}-0.069 \\
{[-0.79,0.66]}\end{array}$ & $\begin{array}{c}-0.21 \\
{[-0.94,0.52]}\end{array}$ & $\begin{array}{c}-0.040 \\
{[-0.69,0.61]}\end{array}$ \\
\hline No of levels & $\begin{array}{c}0.40 \\
{[-0.38,1.19]}\end{array}$ & $\begin{array}{c}0.35 \\
{[-0.49,1.18]}\end{array}$ & $\begin{array}{c}0.23 \\
{[-0.56,1.02]}\end{array}$ & $\begin{array}{c}0.14 \\
{[-0.60,0.87]}\end{array}$ & $\begin{array}{c}0.32 \\
{[-0.34,0.98]}\end{array}$ & $\begin{array}{c}0.37 \\
{[-0.28,1.03]}\end{array}$ \\
\hline Level & $\begin{array}{c}0.088 \\
{[-0.46,0.64]}\end{array}$ & $\begin{array}{c}0.055 \\
{[-0.53,0.64]}\end{array}$ & $\begin{array}{c}0.35 \\
{[-0.20,0.91]}\end{array}$ & $\begin{array}{c}0.068 \\
{[-0.45,0.58]}\end{array}$ & $\begin{array}{c}0.019 \\
{[-0.44,0.48]}\end{array}$ & $\begin{array}{c}-0.18 \\
{[-0.64,0.28]}\end{array}$ \\
\hline Previous symptom duration & $\begin{array}{c}-0.0019 \\
{[-0.01,0.01]}\end{array}$ & $\begin{array}{c}-0.0016 \\
{[-0.01,0.01]}\end{array}$ & $\begin{array}{c}0.0028 \\
{[-0.00,0.01]}\end{array}$ & $\begin{array}{c}-0.00088 \\
{[-0.01,0.01]}\end{array}$ & $\begin{array}{c}0.0018 \\
{[-0.00,0.01]}\end{array}$ & $\begin{array}{c}-0.0014 \\
{[-0.01,0.00]}\end{array}$ \\
\hline Previous neck surgery & $\begin{array}{c}-0.62 \\
{[-2.59,1.36]}\end{array}$ & $\begin{array}{c}-0.50 \\
{[-2.37,1.36]}\end{array}$ & $\begin{array}{c}-1.75 \\
{[-3.73,0.23]}\end{array}$ & $\begin{array}{c}-1.82^{*} \\
{[-3.45,-0.18]}\end{array}$ & $\begin{array}{c}-1.31 \\
{[-3.03,0.41]}\end{array}$ & $\begin{array}{c}-1.02 \\
{[-2.54,0.51]}\end{array}$ \\
\hline Previous neck trauma & $\begin{array}{c}0.24 \\
{[-1.17,1.64]}\end{array}$ & $\begin{array}{c}-0.098 \\
{[-1.42,1.23]}\end{array}$ & $\begin{array}{c}-0.58 \\
{[-1.99,0.83]}\end{array}$ & $\begin{array}{c}-0.37 \\
{[-1.53,0.79]}\end{array}$ & $\begin{array}{c}0.011 \\
{[-1.16,1.18]}\end{array}$ & $\begin{array}{c}-0.53 \\
{[-1.56,0.51]}\end{array}$ \\
\hline Preop radicular pain & $\begin{array}{c}0.60^{* * *} \\
{[0.44,0.76]}\end{array}$ & $\begin{array}{c}0.63^{* * *} \\
{[0.45,0.81]}\end{array}$ & $\begin{array}{c}0.31^{* * *} \\
{[0.13,0.48]}\end{array}$ & $\begin{array}{c}-0.030 \\
{[-0.19,0.13]}\end{array}$ & $\begin{array}{c}0.065 \\
{[-0.08,0.21]}\end{array}$ & $\begin{array}{c}-0.021 \\
{[-0.16,0.12]}\end{array}$ \\
\hline Preop neck pain & $\begin{array}{c}0.14 \\
{[-0.00,0.28]}\end{array}$ & $\begin{array}{c}-0.075 \\
{[-0.23,0.08]}\end{array}$ & $\begin{array}{c}0.66^{* * *} \\
{[0.54,0.78]}\end{array}$ & $\begin{array}{c}0.75^{* * *} \\
{[0.62,0.89]}\end{array}$ & $\begin{array}{c}0.16^{* *} \\
{[0.04,0.28]}\end{array}$ & $\begin{array}{c}-0.035 \\
{[-0.16,0.09]}\end{array}$ \\
\hline Preop headache & $\begin{array}{c}0.078 \\
{[-0.07,0.22]}\end{array}$ & $\begin{array}{c}0.041 \\
{[-0.11,0.19]}\end{array}$ & $\begin{array}{c}0.087 \\
{[-0.06,0.23]}\end{array}$ & $\begin{array}{c}-0.22^{* *} \\
{[-0.35,-0.09]}\end{array}$ & $\begin{array}{c}0.52^{* * *} \\
{[0.41,0.62]}\end{array}$ & $\begin{array}{c}0.54^{* * *} \\
{[0.42,0.66]}\end{array}$ \\
\hline Observations & & 256 & & 255 & & 252 \\
\hline$\overline{\text { Adjusted } R^{2}}$ & & 0.150 & & 0.350 & & 0.261 \\
\hline
\end{tabular}

changes in VAS scores less than \pm 2 is unclear, we estimated the number of patients that had changes in VAS scores of more than \pm 2 for the three pain categories (Table 4). Radicular pain improved $\geq 2$ VAS points in $64 \%$ of the patients, while $6 \%$ of patients experienced a worsening of VAS scor $\leq-2$. Neck pain improved $\geq 2$ VAS points in $55 \%$ of the patients, while $10 \%$ of patients experienced a worsening of VAS score $\leq-2$. Headache improved $\geq 2$ VAS points in $31 \%$ of the patients, while $16 \%$ of patients experienced a worsening of VAS score $\leq-2$.

\section{Paresis}

One hundred and fifty-one of the 249 (61\%) patients had normal muscular strength at the time of surgery. At follow-up, 233/249 (94\%) patients had normal muscular strength.

\section{Myelopathy}

Of the 45 patients with clinical evident myelopathy at the time of surgery, only 16 (35.6\%) had persistent myelopathy 6 months after surgery. 
Table 4 Number of patients with changes in VAS scores of more than $\pm \mathbf{2}$ for the three pain categories, radicular pain, neck pain and headache, separately.

\begin{tabular}{clll}
\hline & & Delta VAS = preoperative - postoperative \\
\hline Pain category & Worsened $(\leq-\mathbf{2 V A S})$ & Unchanged & Improved $(\geq 2$ VAS) \\
Radicular pain & $16(6.2 \%)$ & $78(30.2 \%)$ & $164(63.6 \%)$ \\
Neck pain & $26(10.1 \%)$ & $91(35.3 \%)$ & $141(54.7 \%)$ \\
Headache & $41(15.9 \%)$ & $136(52.7 \%)$ & $81(31.4 \%)$ \\
\hline
\end{tabular}

\section{Working status}

At the onset of symptomatic CDD, $80 \%$ of patients were employed fulltime, $3 \%$ received workers 'compensation for CDD, $4 \%$ received workers 'compensation for reasons other than CDD, $8 \%$ received a disability pension, and $5 \%$ were students, housewives, retired, or unemployed. At the time of surgery, $66 \%$ of patients had received workers 'compensation for 1 month or more. The median sick leave before surgery was 5.0 (0-150) months. Six months after surgery, $48 \%$ of patients had returned to work: however $24 \%$ were still receiving workers 'compensation. The percentage of patients receiving a disability pension increased from $8 \%$, before the onset of symptomatic CDD, to $21 \% 6$ months postoperatively. The increase in the number of patients receiving a disability pension was, related to CDD in all cases but one.

\section{Patient satisfaction}

At the 6-month postoperative control, all patients were asked to score their satisfaction with the surgical result using a VAS scale. The mean reported VAS score was 8.42 , and $200 / 256(78 \%)$ patients reported a score $>8$ (success). Only 27/256 (11\%) patients reported a VAS score $<5$, which indicate that the operation did not fulfil their expectations (failure). Patient satisfaction was then correlated to other measures of surgical outcome at 6 months (Table 5). Patient satisfaction was significantly associated with pain relief after surgery.

\section{Discussion}

\section{Symptom relief after ACDF}

The effectiveness of ACDF in relieving radicular pain secondary to CDD is well documented in both long- and short-term follow-up studies [12,15,28-30]. However, the effectiveness of ACDF in relieving neck pain and headache secondary to CDD remains unclear. In this prospective study of 258 patients, we confirmed the beneficial effect of ACDF on radicular pain. The patients also reported a significant improvement in their neck pain and headache. The reduction in headache, although significant, was only by 0.55 points on the VAS scale, in contrast to the changes observed for radicular and neck pain (VAS score variation of 3.05 and 2.30, respectively). The clinical impact of changes in VAS scores $<2$ is
Table 5 Patient satisfaction 6-months after surgery correlated with selected preoperative variables and other measures of surgical outcome at 6 months.

\begin{tabular}{lc}
\hline Sex & $\begin{array}{c}\text { Patient } \\
\text { satisfaction }\end{array}$ \\
\hline Age & -0.19 \\
& {$[-0.85,0.46]$} \\
Previous symptom duration & -0.031 \\
& {$[-0.07,0.00]$} \\
Delta radiculopathy & 0.00014 \\
& {$[-0.01,0.01]$} \\
Delta neck pain & $0.33^{* * *}$ \\
& {$[0.24,0.42]$} \\
Delta headache & $0.22^{* * *}$ \\
& {$[0.12,0.31]$} \\
\hline Observations & $0.20^{* *}$ \\
\hline
\end{tabular}

(Linear univariate regression analysis).

$95 \%$ confidence intervals are shown in brackets

${ }^{*} p<0.05,{ }^{* *} p<0.01,{ }^{* * *} p<0.001$

unclear. An improvement in VAS score $\geq 2$ was observed in $64 \%, 55 \%$, and $31 \%$ of patients, for radicular pain, neck pain, and headache, respectively. Almost all patients in our series had radicular pain: therefore, our cohort cannot be used to answer the question concerning the effect of ACDF on neck pain or discogenic headache in patients with mild or no radicular pain. Schofferman et al. published a series of nine patients that allowed them to conclude that ACDF is an effective treatment for discogenic headache [31]. In a recent publication, Laimi et al. reported a low probability of association between headache and CDD [32]. We remain reluctant to offer ACDF to patients with dominating neck pain or headache who have little or no radicular pain.

\section{Working status}

The percentage of patients that returned to work within 6 months of surgery was lower than expected [28]. The 
most likely explanations for this result are symptom persistence, passive approach with respect to motivating the patient to return to work, and that surgery in some patients was regarded as the last necessary step for the collection of a permanent disability pension. More effort is required to assist the return of patients to the workplace as early as possible. Bhandari et al. reported that $28 \%$ of their patient cohort had not returned to work one year after cervical discectomy [33]. These authors found that long preoperative sick leave and persistent postoperative neck pain were associated with not returning to work after surgery. Age and disability claims also influenced the rates of return to work. Steinmetz et al. have studied return to work in a cohort of patients who had workers compensation as their primary insurance. They found $42 \%$ return to work 6 months after ACDF and $55 \%$ return to work 6 months after cervical disc arthroplasty [34].

\section{Patient satisfaction}

Two hundred out of the 256 (78\%) patients evaluated the surgical result as successful. Only $27 / 256$ (11\%) patients classified the surgical result as a failure. A $78 \%$ success rate after surgery for CDD must be regarded as acceptable. Patient satisfaction is often evaluated using the Odom Criteria [35]. This said, the VAS scale is an accepted tool to evaluate patient satisfaction[26].

\section{Prognostic factors}

In our series, we found a significant correlation between high preoperative pain intensity and decrease in pain intensity after surgery, for all three pain categories. We found no significant correlation between symptom reduction after ACDF and sex, age, number of levels fused, disc level fused, fusion method (AICG or PEEK), previous neck surgery (except for neck pain), previous neck trauma or preoperative symptom duration. The most likely explanation for the lack of identification of prognostic factors is that we selected the best candidates for surgery based on previous knowledge $[4,5]$. However we were surprised by the fact that symptom duration failed to influence the final surgery outcome, as many of our patients had a rather long preoperative symptom duration. This finding is in contrast with earlier reports on symptomatic CDD and herniated lumbar disc with sciatica [6,7]. An unfavorable postoperative outcome was reported in cases where symptom duration exceeded 6 months in patients treated for herniated lumbar disc and sciatica [6]. Our data suggest that a lengthy duration of symptoms does not influence outcomes.

\section{Fusion with PEEK cage versus AICG}

Anterior cervical decompression and fusion with autologous bone graft has been the standard treatment for
CDD for more than 50 years [9]. In recent years, many surgeons have replaced autologous bone grafting with an artificial cage and they report equivalent clinical outcomes after this shift in surgical procedure [12,14-17]. Our study confirmed the results of these previous studies. We found no significant differences between the type of fusion in relation to reduction of radicular pain, neck pain, or headache. We have reported the presence of similar complication rates for patients fused with a PEEK cage or with AICG, with the exeption of the absence of donor site morbidity in patients fused with a PEEK cage [11]. The absence of donor site morbidity, the shorter operation time, and the equivalent clinical results associated with the use of PEEK cages lead us to prefer this type of fusion to AICG.

\section{Optimal surgical procedure for CDD}

There is no clear consensus regarding the optimal surgical procedure for CDD [2,36-38]. Which procedure provides the best clinical outcomes: anterior cervical discectomy alone (ACD), ACDF, discectomy with intervertebral fusion and instrumentation (ACDFI), or cervical arthroplasty? A recent prospective randomized study comparing ACD, ACDF and ACDFI in patients with CDD showed no significant differences in clinical outcomes at the 2 year follow up[37]. However, patients operated with ACD had a higher rate of segmental kyphosis than patients operated with ACDF or ACDFI. Some authors report lesser graft dislocations and graft collapse and higher fusion rates after ACDFI compared with ACDF [13,39,39-42]. On the other hand, the complication rate after ACDFI is somewhat higher compared with ACDF $[12,13,41]$. ACD, ACDF and ACDFI reduce segmental motion and cause heightened stress on the discs below and above the fusion, which in turn may induce adjacent-level degeneration [43-46]. The main arguments in favor of cervical arthroplasty are the preservation of segmental motion and a lower risk of adjacent-level disc degeneration. The results of randomized, controlled clinical trials comparing cervical disc arthroplasty with ACDF are now emerging [45,47-54]. The follow-up times in the arthroplasty studies are relatively short, however there is a tendency for slightly improved outcomes after cervical prosthesis compared with ACDF. Our routine procedure has so far been ACDF, (both single-level and two-level ACDF). Based on the current literature, we see no reason to change this strategy at this time, although we accept that ACD, ACDFI, and prosthesis probably provide similar clinical outcomes. If the longterm clinical outcome of cervical arthroplasty is demonstrated to be superior to ACDF, we will change our treatment strategy. 


\section{Limitations of the study}

- The patients were not randomized to fusion with either AICG or PEEK-cage. The type of fusion was in each case decided by the surgeon. This may cause a bias in the material.

- Ideally the outcome after ACDF for CDD should have been compared with an equivalent group managed with conservative measures.

- The follow-up evaluation was done by the surgeons and not an independent investigator, this may have influenced the final result.

\section{Conclusions}

- ACDF is an effective treatment for radicular pain in selected patients with CDD (patients evaluated 6 months after surgery).

- Because of similar clinical outcome and lack of donor site morbidity when using PEEK, we now prefer fusion with PEEK-cage to AICG.

- Lengthy symptom duration was not a negative prognostic marker in our patient population.

- The number of patients who returned to work 6 months after surgery was lower than expected.

\section{Author details}

'Department of Neurosurgery-Rikshospitalet, Oslo University Hospital, N-0027 Oslo, Norway. ${ }^{2}$ Department of Neurosurgery-Ullevål, Oslo University Hospital, N-0407 Oslo, Norway. ${ }^{3}$ Faculty of Medicine, University of Oslo, Oslo, Norway.

\section{Authors' contributions}

BL; libb@ulleval.no; Data collection, statistics, data analysis, discussion and writing. PAR; rnpl@uus.no; Statistics, discussion and writing. JS: jarle. sundseth@rikshospitalet.no; Data collection and discussion.EH; heej@uus.no; Data collection, statistics, data analysis, discussion and writing. All authors have read and approved the final manuscript.

\section{Competing interests}

The authors did not receive financial support in conjunction with the generation of this article. The authors have no personal or institutional financial interest in drugs, materials, or devices described in this article.

Received: 20 May 2009 Accepted: 21 March 2010

Published: 21 March 2010

\section{References}

1. Radhakrishnan K, Litchy WJ, O'Fallon WM, Kurland LT: Epidemiology of cervical radiculopathy. A population-based study from Rochester, Minnesota, 1976 through 1990. Brain 1994, 117(Pt 2):325-335.

2. Jacobs WC, Anderson PG, Limbeek J, Willems PC, Pavlov P: Single or double-level anterior interbody fusion techniques for cervical degenerative disc disease. Cochrane Database Syst Rev 2004, CD004958.

3. Patil $P G$, Turner DA, Pietrobon R: National trends in surgical procedures for degenerative cervical spine disease: 1990-2000. Neurosurgery 2005, 57:753-758.

4. Peolsson A, Peolsson M: Predictive factors for long-term outcome of anterior cervical decompression and fusion: a multivariate data analysis. Eur Spine J 2008, 17:406-414.

5. Anderson PA, Subach BR, Riew KD: Predictors of outcome after anterior cervical discectomy and fusion: a multivariate analysis. Spine 2009, 34:161-166.
6. Nygaard $\mathrm{OP}$, Romner B, Trumpy JH: Duration of symptoms as a predictor of outcome after lumbar disc surgery. Acta Neurochir (Wien) 1994, 128:53-56.

7. Bertalanffy $H$, Eggert HR: Clinical long-term results of anterior discectomy without fusion for treatment of cervical radiculopathy and myelopathy. A follow-up of 164 cases. Acta Neurochir (Wien) 1988, 90:127-135.

8. Cloward RB: The anterior approach for removal of ruptured cervical discs. J Neurosurg 1958, 15:602-616.

9. Robinson RA, Smith GW: Anterolateral cervical disc removal and interbody fusion for cervical disc syndrome. Bull Johs Hopkins Hospital $1955,96: 223-224$.

10. Sonntag VK, Han PP, Vishteh AG: Anterior cervical discectomy. Neurosurgery 2001, 49:909-912.

11. Lied B, Sundseth J, Helseth E: Immediate (0-6 h), early (6-72 h) and late $(>72 \mathrm{~h})$ complications after anterior cervical discectomy with fusion for cervical disc degeneration; discharge six hours after operation is feasible. Acta Neurochir (Wien) 2008, 150:111-118.

12. Hacker RJ, Cauthen JC, Gilbert TJ, Griffith SL: A prospective randomized multicenter clinical evaluation of an anterior cervical fusion cage. Spine 2000, 25:2646-2654.

13. Fountas KN, Kapsalaki EZ, Nikolakakos LG, Smisson HF, Johnston KW, Grigorian AA, et al: Anterior cervical discectomy and fusion associated complications. Spine 2007, 32:2310-2317.

14. Cho DY, Liau WR, Lee WY, Liu JT, Chiu CL, Sheu PC: Preliminary experience using a polyetheretherketone (PEEK) cage in the treatment of cervical disc disease. Neurosurgery 2002, 51:1343-1349.

15. Peolsson A: Investigation of clinically important benefit of anterior cervical decompression and fusion. Eur Spine J 2007, 16:507-514.

16. Moreland DB, Asch HL, Clabeaux DE, Castiglia GJ, Czajka GA, Lewis PJ, et al: Anterior cervical discectomy and fusion with implantable titanium cage: initial impressions, patient outcomes and comparison to fusion with allograft. Spine J 2004, 4:184-191.

17. Thome C, Krauss JK, Zevgaridis D: A prospective clinical comparison of rectangular titanium cages and iliac crest autografts in anterior cervical discectomy and fusion. Neurosurg Rev 2004, 27:34-41.

18. Fernandez-Fairen M, Sala P, Dufoo M Jr, Ballester J, Murcia A, Merzthal L: Anterior cervical fusion with tantalum implant: a prospective randomized controlled study. Spine (Phila Pa 1976) 2008, 33:465-472.

19. Garcia S, Lozano ML, Gatell JM, Soriano E, Ramon R, Sanmiguel JG: Prophylaxis against infection. Single-dose cefonicid compared with multiple-dose cefamandole. J Bone Joint Surg Am 1991, 73:1044-1048.

20. Hill C, Flamant R, Mazas F, Evrard J: Prophylactic cefazolin versus placebo in total hip replacement. Report of a multicentre double-blind randomised trial. Lancet 1981, 1:795-796.

21. Rubinstein E, Findler G, Amit P, Shaked I: Perioperative prophylactic cephazolin in spinal surgery. A double-blind placebo-controlled trial. J Bone Joint Surg Br 1994, 76:99-102.

22. Her Majestys Stationary Office London: Medical Research Council. Aida to examination of the peripheral nervous system. Memorandum no 451981.

23. Huskisson EC: Measurement of pain. J Rheumatol 1982, 9:768-769.

24. DeLoach LJ, Higgins MS, Caplan AB, Stiff JL: The visual analog scale in the immediate postoperative period: intrasubject variability and correlation with a numeric scale. Anesth Analg 1998, 86:102-106.

25. Pool JJ, Ostelo RW, Hoving JL, Bouter LM, de Vet HC: Minimal clinically important change of the Neck Disability Index and the Numerical Rating Scale for patients with neck pain. Spine (Phila Pa 1976) 2007, 32:3047-3051.

26. Brokelman RB, van Loon CJ, Rijnberg WJ: Patient versus surgeon satisfaction after total hip arthroplasty. J Bone Joint Surg Br 2003, 85:495-498.

27. Dolan P, Sutton M: Mapping visual analogue scale health state valuations onto standard gamble and time trade-off values. Soc Sci Med 1997, 44:1519-1530.

28. Goldberg EJ, Singh K, Van U, Garretson R, An HS: Comparing outcomes of anterior cervical discectomy and fusion in workman's versus nonworkman's compensation population. Spine J 2002, 2:408-414.

29. Gore DR, Sepic SB: Anterior discectomy and fusion for painful cervical disc disease. A report of 50 patients with an average follow-up of 21 years. Spine 1998, 23:2047-2051. 
30. Jagannathan J, Shaffrey Cl, Oskouian RJ, Dumont AS, Herrold C, Sansur CA et al: Radiographic and clinical outcomes following single-level anterior cervical discectomy and allograft fusion without plate placement or cervical collar. J Neurosurg Spine 2008, 8:420-428.

31. Schofferman J, Garges K, Goldthwaite N, Koestler M, Libby E: Upper cervical anterior diskectomy and fusion improves discogenic cervical headaches. Spine 2002, 27:2240-2244

32. Laimi K, Erkintalo M, Metsahonkala L, Vahlberg T, Mikkelsson M, Sonninen P, et al: Adolescent disc degeneration-no headache association. Cephalalgia 2007, 27:14-21.

33. Bhandari M, Louw D, Reddy K: Predictors of return to work after anterior cervical discectomy. J Spinal Disord 1999, 12:94-98.

34. Steinmetz MP, Patel R, Traynelis V, Resnick DK, Anderson PA: Cervical disc arthroplasty compared with fusion in a workers' compensation population. Neurosurgery 2008, 63:741-747.

35. Odom GL, Finney W, Woodhall B: Cervical disk lesions. J Am Med Assoc 1958, 166:23-28.

36. Samartzis D, Shen FH, Matthews DK, Yoon ST, Goldberg EJ, An HS: Comparison of allograft to autograft in multilevel anterior cervical discectomy and fusion with rigid plate fixation. Spine J 2003, 3:451-459.

37. Xie JC, Hurlbert RJ: Discectomy versus discectomy with fusion versus discectomy with fusion and instrumentation: a prospective randomized study. Neurosurgery 2007, 61:107-116.

38. Samartzis D, Shen FH, Lyon C, Phillips M, Goldberg EJ, An HS: Does rigid instrumentation increase the fusion rate in one-level anterior cervical discectomy and fusion? Spine J 2004, 4:636-643.

39. Fraser JF, Hartl R: Anterior approaches to fusion of the cervical spine: a metaanalysis of fusion rates. J Neurosurg Spine 2007, 6:298-303.

40. Wang JC, McDonough PW, Endow KK, Delamarter RB: Increased fusion rates with cervical plating for two-level anterior cervical discectomy and fusion. Spine 2000, 25:41-45.

41. Cho DY, Lee WY, Sheu PC: Treatment of multilevel cervical fusion with cages. Surg Neurol 2004, 62:378-85, discussion.

42. Zoega B, Karrholm J, Lind B: Plate fixation adds stability to two-level anterior fusion in the cervical spine: a randomized study using radiostereometry. Eur Spine J 1998, 7:302-307.

43. Hilibrand AS, Carlson GD, Palumbo MA, Jones PK, Bohlman HH: Radiculopathy and myelopathy at segments adjacent to the site of a previous anterior cervical arthrodesis. J Bone Joint Surg Am 1999, 81:519-528.

44. Ishihara H, Kanamori M, Kawaguchi Y, Nakamura H, Kimura T: Adjacent segment disease after anterior cervical interbody fusion. Spine J 2004, 4:624-628.

45. Nabhan A, Steudel WI, Nabhan A, Pape D, Ishak B: Segmental kinematics and adjacent level degeneration following disc replacement versus fusion: RCT with three years of follow-up. J Long Term Eff Med Implants 2007, 17:229-236.

46. Seo M, Choi D: Adjacent segment disease after fusion for cervical spondylosis; myth or reality? Br J Neurosurg 2008, 22:195-199.

47. Heller JG, Sasso RC, Papadopoulos SM, Anderson PA, Fessler RG, Hacker RJ, et al: Comparison of BRYAN cervical disc arthroplasty with anterior cervical decompression and fusion: clinical and radiographic results of a randomized, controlled, clinical trial. Spine 2009, 34:101-107.

48. Kim SW, Limson MA, Kim SB, Arbatin JJ, Chang KY, Park MS, et al: Comparison of radiographic changes after ACDF versus Bryan disc arthroplasty in single and bi-level cases. Eur Spine J 2009, 18:218-231.

49. Mummaneni PV, Burkus JK, Haid RW, Traynelis VC, Zdeblick TA: Clinical and radiographic analysis of cervical disc arthroplasty compared with allograft fusion: a randomized controlled clinical trial. J Neurosurg Spine 2007, 6:198-209.

50. Nabhan A, Ahlhelm F, Pitzen T, Steudel Wl, Jung J, Shariat K, et al: Disc replacement using Pro-Disc $C$ versus fusion: a prospective randomised and controlled radiographic and clinical study. Eur Spine J 2007, 16:423-430.

51. Sasso RC, Smucker JD, Hacker RJ, Heller JG: Clinical outcomes of BRYAN cervical disc arthroplasty: a prospective, randomized, controlled, multicenter trial with 24-month follow-up. J Spinal Disord Tech 2007, 20:481-491.

52. Sasso RC, Smucker JD, Hacker RJ, Heller JG: Artificial disc versus fusion: a prospective, randomized study with 2-year follow-up on 99 patients. Spine 2007, 32:2933-2940.
53. Sasso RC, Best NM: Cervical kinematics after fusion and bryan disc arthroplasty. J Spinal Disord Tech 2008, 21:19-22.

54. Sasso RC, Best NM, Metcalf NH, Anderson PA: Motion analysis of bryan cervical disc arthroplasty versus anterior discectomy and fusion: results from a prospective, randomized, multicenter, clinical trial. J Spinal Disord Tech 2008, 21:393-399.

\section{Pre-publication history}

The pre-publication history for this paper can be accessed here: http://www. biomedcentral.com/1471-2482/10/10/prepub

doi:10.1186/1471-2482-10-10

Cite this article as: Lied et al:: Anterior cervical discectomy with fusion in patients with cervical disc degeneration: a prospective outcome study of 258 patients (181 fused with autologous bone graft and 77 fused with a PEEK cage). BMC Surgery 2010 10:10.

\section{Submit your next manuscript to BioMed Central and take full advantage of:}

- Convenient online submission

- Thorough peer review

- No space constraints or color figure charges

- Immediate publication on acceptance

- Inclusion in PubMed, CAS, Scopus and Google Scholar

- Research which is freely available for redistribution

Submit your manuscript at www.biomedcentral com/submit
Ciomed Central 